\title{
Competências do professor de educação física e formação profissional
}

\author{
Rodrigo Nuno Peiró Correia \\ Osvaldo Luiz Ferraz \\ Escola de Educação Física e Esporte da USP, São Paulo, SP, Brasil
}

\begin{abstract}
Resumo: Este estudo tem como objetivo identificar as competências necessárias aos professores de Educação Física da Educação Básica, na perspectiva dos docentes da rede pública de ensino do estado de São Paulo, licenciados e egressos da Escola de Educação Física e Esporte da Universidade de São Paulo, a partir do ano de 1995. Trata-se de uma pesquisa qualitativa, de natureza não experimental, consistindo em dois estudos (diagnóstico e aprofundamento). Como instrumentos, foram utilizados questionário e entrevista semi-estruturada.Verificou-se que os docentes julgam importante mobilizar determinados conhecimentos hierarquizados ou associados durante a prática docente, tais como: conhecimentos didático-pedagógicos, conhecimentos técnicos e bagagem cultural, inseridos no contexto atual e considerando as transformações culturais, sociais, políticas, econômicas e educacionais ocorridas ao longo da história. Ficou evidenciada, neste estudo, a relevância da formação continuada para os professores de Educação Física, que a consideraram imprescindível em complementação à formação inicial.
\end{abstract}

Palavras-chave: Competências. Educação superior. Educação continuada.

\section{The physical education teacher's competences and professional formation}

\begin{abstract}
This study has as objective identifies the necessary competences to the physical education teachers of the basic education, in the teachers' of the public network of teaching of the São Paulo state perspective, licentiates and exits of the Physical Education School and Sport of the São Paulo University starting from 1995. It is a qualitative research, of nature no experimental, consisting of two studies (diagnostic and deepening). As instruments, questionnaire and semi-structured interview were used. It happened what the teachers judge importantly mobilize determined knowledges placed in a hierarchy or associated during the teaching practice, such as: knowledges pedagogic-educational, technical knowledges and cultural luggage, inserted in the current context and considering the cultural, social, political, economical and education transformations occurred along the history. There was shown up in this study the relevance of the formation continued for the teachers of Physical Education, who found her essential and basic added to the initial formation.
\end{abstract}

Key Words: Competences. Higher education. Continuous education.

\section{Introdução}

O contexto histórico em que vivemos na atualidade caracteriza-se por marcantes transformações políticas, sociais, econômicas, culturais e educacionais. Estas transformações exigem reestruturação da sociedade em seus diferentes setores (RIOS, 2005).

No âmbito educacional, as mudanças ocorridas nos últimos anos vêm provocando alterações significativas no contexto escolar que, por conseguinte, refletem na atuação e no comportamento de seus docentes. Desta forma, torna-se necessário reconstruir e atualizar a perspectiva que se tem sobre as competências docentes capazes de responder aos novos desafios.

As competências profissionais aparecem diante aos acontecimentos, às incertezas, às situações de imprevisto, na instabilidade e na urgência. Ser competente é saber combinar recursos e mobilizá-los em um contexto (LE BOTERF, 2003). Como exemplo de recurso a ser mobilizado, é o conhecimento, que, segundo Nonaka e Takeushi (1997), é subdividido em "conhecimento tácito" e "conhecimento explícito". O primeiro é o conhecimento pessoal incorporado à experiência individual e envolve fatores intangíveis, tais como: crenças pessoais; perspectivas; valores; intuições e emoções. O segundo é o conhecimento que pode ser articulado na linguagem formal e é facilmente transmitido, sistematizado e comunicado.

\footnotetext{
A formação docente deve ser entendida como um processo inacabado, em constante movimento de reconversão, devido à natureza do conhecimento necessário ao trabalho docente na escola. Este conhecimento está em constante
} 
produção, reformulação e síntese e, em função desta modificação, com o passar do tempo, exige-se a preparação de profissionais capazes de adaptar ou alterar a sua prática profissional à luz dessa evolução (MORFORD, 1972). Além disso, a instituição escolar com suas práticas, hábitos e valores deve ser reconhecida como um espaço privilegiado nessa formação profissional (FERRAZ, 2000).

Em termos profissionais, a preparação do Licenciado em Educação Física está orientada para sua atuação na escolarização básica, planejando, implementando e avaliando programas de Educação Física escolar. Nesse sentido, são fundamentais os conhecimentos relativos aos aspectos: a compreensão adequada do componente curricular Educação Física e sua relação com os demais componentes curriculares, e o entendimento dos propósitos e requisitos da educação formal (FERRAZ, 2000). Sendo assim, o licenciado deve ser dotado de competências de ensino na sua área do saber, além da compreensão da realidade social brasileira (seus valores, representações, história e práticas institucionais), de modo a poder assumir uma perspectiva de ação crítica e responsável na transformação dessa realidade (UNIVERSIDADE DE SÃO PAULO, 2004).

Portanto, devemos ser capazes de responder a algumas perguntas, tais como: $O$ que é ser docente na sociedade atual? Como formar professores? A formação de professores permite a compreensão da complexidade das realidades sociais e contribui para sua transformação? Serão docentes reprodutores de saber alheio ou produtores de saber próprio? Resumindo, quais são as competências que o professor de Educação Física escolar deverá possuir, diante de uma sociedade em constante transformação?

\section{Justificativa}

Diante do atual panorama em que se encontram as aulas de Educação Física na rede pública de ensino, no que diz respeito ao baixo aproveitamento, deficiências na aprendizagem e a escassa retenção de conteúdos por grande parte dos alunos que as frequentam, torna-se relevante uma investigação das competências necessárias aos professores no exercício da docência escolar, para que este quadro possa ser melhorado. A partir do momento em que essas competências se tornarem mais evidentes, elas poderão contribuir satisfatoriamente para subsidiar a estruturação de cursos de formação de professores (licenciatura e pós-graduação).

Todavia, é preciso considerar as precárias condições de trabalho em que os professores estão inseridos, tais como: jornada de trabalho com número elevado de aulas, tempo escasso para planejamento, baixos salários, número excessivo de alunos por sala de aula, dificuldades em se envolver com cursos de especialização e, até mesmo, em adquirir livros devido a seu alto custo.

A competência de um bom profissional assenta-se no conhecimento tácito aliado ao conhecimento da ciência e das técnicas, trazendo-lhes uma dimensão criativa. Conhecimento tácito é aquele que o indivíduo adquiriu ao longo da vida e geralmente é difícil de ser formalizado ou explicado a outra pessoa, pois é subjetivo e inerente a ele. A palavra tácito vem do latim tacitus, que significa: "não expresso por palavras". Esses conhecimentos tácitos, construídos na prática profissional precisam ser identificados e valorizados na formação profissional ( $\underline{\text { SCHÖN }}$, 1988).

Uma sociedade em constante transformação necessita de sujeitos capazes de se adaptarem a novas realidades em busca de uma autonomia cidadã. Para tal, a escolarização precisa abandonar a mera transmissão de conhecimentos implicando, necessariamente, o redimensionamento da profissão docente (IMBERNÓN, 2000). Agravando essa situação, os professores, de uma maneira geral, apresentam resistência em romper alguns paradigmas préexistentes no campo da educação escolarizada, edificados ao longo da história.

Considera-se que quaisquer intervenções no sentido de qualificar o projeto pedagógico da rede de ensino não podem prescindir do conhecimento que os professores já têm sobre seu trabalho e suas competências. Daí a relevância deste estudo para os cursos de formação de professores.

\section{Objetivos}

A pesquisa tem como objetivo analisar as competências profissionais necessárias aos professores de Educação Física da Educação Básica, na perspectiva dos docentes da rede pública de ensino do estado de São Paulo, licenciados e egressos da Escola de Educação 
Física e Esporte da Universidade de São Paulo (EEFE-USP) a partir do ano de 1995.

\section{Metodologia}

Esta pesquisa foi aprovada pelo Comitê de Ética em Pesquisa da Escola de Educação Física e Esporte da Universidade de São Paulo, através do parecer número 2007/22, e os sujeitos do estudo assinaram o Termo de Consentimento Livre e Esclarecido.

É caracterizada como sendo de natureza não experimental (THOMAS; NELSON, 2002) e foi conduzida mediante as orientações metodológicas de Lüdke e André (1986) e Triviños (1987), consistindo em dois estudos.

\section{Estudo I - Competências profissionais para o ensino da Educação Física: diagnóstico}

O objetivo deste estudo foi o de analisar a perspectiva que os professores têm sobre as competências profissionais necessárias ao ensino da Educação Física na rede pública de ensino municipal e estadual de São Paulo.

Em se tratando de um diagnóstico inicial, foram convidados a participar do estudo, os professores licenciados pela Escola de Educação Física da USP que ministram aulas de Educação Física no sistema de ensino público de educação básica do estado de São Paulo. Foram selecionados os professores licenciados a partir da reestruturação curricular ocorrida no ano de 1995. Esta escolha é decorrente da reestruturação curricular ocorrida nesta data que elaborou um Projeto Político Pedagógico de formação de professores específico para a Licenciatura, posterior ao curso de Bacharelado.

\section{Sujeitos}

A amostra foi constituída por professores licenciados pela EEFE-USP a partir de 1995, compondo um universo de 15 professores (dados fornecidos pela Secretaria de Graduação da Escola de Educação Física e Esporte da USP). Após email enviado a todos os licenciados desde 1995, obtivemos resposta de 30 professores. Desses 30 professores, 15 foram escolhidos por atuarem na rede pública de ensino. Os outros 15 não foram selecionados para este estudo devido ao fato de estarem atuando fora da educação básica pública.

\section{Instrumento}

O instrumento utilizado foi um questionário (Anexo I) com 20 questões referentes a: (1) Aspectos da graduação; (2) Atuação profissional e (3) Atualização profissional e cursos de pósgraduação.

\section{Procedimentos de coleta dos dados}

Os professores foram contatados por telefone e, após concordarem participar do estudo, os questionários foram enviados por e-mail e/ou correio.

\section{Procedimentos para análise dos dados}

As categorias propostas para análise dos dados serão explicitadas conjuntamente à apresentação e discussão dos resultados. Inicialmente, os dados foram organizados a partir dos seguintes temas: "conhecimento didáticopedagógico", "conhecimento técnico" (matéria/área) e "bagagem cultural" presentes na intervenção docente em Educação Física.

\section{Estudo II - Competências profissionais para o ensino da educação física: aprofundamento}

Foi realizada uma entrevista semi-estruturada com os professores, utilizando-se um gravador de áudio e fitas k-7, para posterior transcrição das respostas.

Optou-se pela entrevista semi-estruturada para aprofundar a identificação e as formas de apreensão das competências profissionais necessárias à ação docente. A entrevista semiestruturada representa um dos instrumentos básicos para a coleta de dados nesse tipo de pesquisa, permitindo ao pesquisador a captação imediata das informações sobre o tema proposto (LÜDKE e ANDRÉ, 1986; TRIVIÑOS, 1987).

\section{Sujeitos}

Foram entrevistados 06 (seis) professores pertencentes à amostra do Estudo I. O critério utilizado para a seleção dos sujeitos foi o de sorteio.

\section{Instrumento}

O roteiro da entrevista semi-estruturada (Anexo II) foi dividido em duas partes. A primeira parte é um diagnóstico da formação e do perfil profissional do professor. A segunda parte da entrevista se constitui de três questões abertas, sendo a primeira referente aos conhecimentos que o professor mobiliza diante do seu trabalho docente; a segunda questão se relaciona aos aspectos/ objetivos/ conteúdos que seriam mais 
valorizados pelos docentes, na implantação de um curso de formação continuada para professores de Educação Física; e, a terceira questão, refere-se às transformações culturais, sociais, políticas, econômicas e educacionais ao longo da história, que podem influenciar a ação do profissional docente na escola.

\section{Procedimentos de coleta de dados}

Os dados foram coletados pelo próprio pesquisador, nas escolas onde os professores trabalham e, também, em outros locais de comum acordo. Os profissionais foram convidados a participar da pesquisa, por meio de um contato prévio e, após o consentimento, foram realizadas entrevistas individuais com cada professor.

\section{Procedimentos de análise de dados}

Para as entrevistas, foi utilizado o método de Análise de Conteúdo de Triviños (1987). De acordo com o autor, este método se constitui de um conjunto de técnicas de análise das comunicações que procura obter indicadores (quantitativos ou não) para que o pesquisador possa elaborar inferências de conhecimentos que circunscrevem a produção/recepção das mensagens analisadas. É importante esclarecer que os procedimentos utilizados neste método enfatizam a sistematização e a descrição objetiva do conteúdo das mensagens.

O referido método pode ser dividido em três fases distintas: pré-análise, descrição analítica e interpretação inferencial. Segundo Triviños (1987), a pré-análise é a organização do material. Durante a descrição analítica, o material que constitui o corpo do documento é submetido a um estudo aprofundado, orientado inicialmente pelas hipóteses e referenciais teóricos. A partir desse ponto, é realizada a codificação, a classificação e a categorização do material para se constituírem os quadros de referência. Busca-se ainda, sínteses coincidentes e divergentes de idéias ou a expressão de concepções singulares, ou seja, que não estejam especificamente unidas a alguma teoria. $\mathrm{Na}$ fase de interpretação inferencial ocorre a reflexão do pesquisador, com a subjetividade inerente a este processo, a partir dos materiais empíricos onde se estabelecem relações que aprofundam as conexões das idéias. Na interação dos materiais é preciso que o pesquisador aprofunde sua análise tentando desvendar o conteúdo latente que eles possuem, descobrindo características e tendências dos fenômenos sociais que se analisam.

\section{Resultados e Discussão Estudo I}

A análise dos dados referentes ao questionário do Estudo I, partindo dos pressupostos teóricos presentes na referência bibliográfica consultada, permitiu inferir que os professores valorizam e consideram imprescindível para sua formação profissional, a aquisição dos seguintes conhecimentos:

a) Didático-pedagógicos: relacionados à didática de ensino, ou seja, como os conteúdos presentes no planejamento pedagógico são transmitidos, de forma a serem assimilados pelos alunos. Exemplos desse tipo de conhecimento são: métodos de ensino, técnicas de comunicação verbal e não verbal para conseguir e manter a atenção dos alunos.

b) Técnico (matéria/área): conhecimento específico sobre determinado conteúdo da Educação Física a ser ensinado, tais como: mudanças fisiológicas durante a atividade física, história dos jogos olímpicos, modalidades esportivas, jogos cooperativos, ritmo.

c) Bagagem cultural: conhecimentos adquiridos pelos professores em seu histórico de vida, considerando aspectos culturais, educacionais, sociais, éticos e morais. Por exemplo, as relações entre a educação escolarizada e a política, o corpo e a modernidade, entre outros.

A necessidade destes conhecimentos tornouse evidente nas respostas dos professores. Por exemplo, 62\% dos professores responderam que as disciplinas específicas da Educação Física correspondentes ao conhecimento técnico (matéria/área) são as mais importantes. Já 38\% dos docentes responderam que as disciplinas voltadas para a licenciatura, as quais abrangem os conhecimentos didático-pedagógicos e bagagem cultural são primordiais.

A escassez destes conhecimentos ficou explícita no depoimento dos professores em relação às dificuldades apresentadas durante a atuação profissional, onde a mais citada foi a deficiência de conhecimento técnico/área $(18,3 \%)$.

Em seguida, apareceram outras dificuldades tais como: pouco material e espaço inadequado para as aulas de Educação Física (15,2\%); baixos salários $(9,1 \%)$; falta de apoio da direção $(9,1 \%)$; indisciplina dos alunos $(9,1 \%)$; desunião entre os professores $(9,1 \%)$; relação interpessoal precária entre professor e aluno $(9,1 \%)$. 
Ainda em complemento ao que foi citado pelos professores, foram apontados outros problemas, tais como: como excesso de alunos por sala de aula; ausência de formação continuada; baixa autonomia do professor; desinteresse dos alunos; planejamento inadequado; desrespeito aos valores humanos e dificuldades em avaliar os alunos; cada uma com 3\% de incidência.

Para confirmar esta necessidade dos professores de adquirir mais conhecimentos didático-pedagógicos e técnicos (matéria/área), os professores relataram que assimilaram a maior parte deles no campo de trabalho, durante sua atuação profissional $(64,7 \%)$, ao passo que apenas $35,3 \%$ os adquiriram durante os cursos de graduação.

Os percentuais citados no parágrafo anterior indicam que estes conhecimentos que estão sendo ensinados nos cursos de formação profissional ainda são insuficientes para a prática profissional. Esses conhecimentos estão sendo adquiridos, em maior parte, durante a atuação profissional, como ficou evidenciado nos depoimentos. Este fato pode gerar nos professores, receio, insegurança e deficiências de conhecimento, principalmente ao iniciarem suas atuações profissionais, fazendo com que muitos venham a procurar alternativas para suprirem tais dificuldades. Destaca-se que somente um professor, dos quinze participantes do Estudo I, considerou-se muito seguro para atuar profissionalmente.

Quanto às respostas dos professores com relação ao que consideraram como falha mais relevante no processo de formação acadêmica, $42 \%$ relataram falta de conhecimento prático. Somando-se a este fato, para $67 \%$ dos professores, o mais importante em um curso de graduação em Educação Física é que ele relacione teoria e prática. Ao responderem se o curso de Educação Física que realizaram integrou teoria e prática, $40 \%$ alegaram que "não"; 40\% declararam que "em parte" e somente $20 \%$, respondeu que "houve" esta integração.

Diante do exposto, consideramos ser imprescindível que estes conhecimentos sejam transmitidos aos professores durante sua formação inicial para que, desta forma, tenham embasamento suficiente para melhor êxito em sua atuação profissional. Ficou demonstrado que a aplicação desses conhecimentos pelos alunos nas atividades de estágio, durante sua formação acadêmica, precisa ser mais enfatizada. Ainda pode-se observar que, na visão dos professores, estes conhecimentos também são importantes na formação continuada (pós-graduação, cursos de extensão universitária).

Analisando-se a descrição dos dados do questionário, a relevância da formação continuada tornou-se transparente, levando-nos a confirmar que apenas a formação inicial do professor não é suficiente para o processo de formação profissional. Este fato corroborado por vários pesquisadores em educação, tais como Nóvoa (1995), Schön (1988), Imbernón (2000), Perrenoud; Paquay; Altet; Charlier (2001), além dos Referenciais para a Formação de Professores Polivalentes (BRASIL,1998), implica no pressuposto de que a formação e o desenvolvimento profissional é um processo contínuo e permanente, influenciado pelo modo como o docente age e pensa em diferentes fases e situações da vida, considerando-se tanto a vida profissional como a pessoal.

Outro elemento relevante que aparece nas respostas dos docentes pesquisados é a noção de um professor que elabora hipóteses, aplica, analisa, interpreta e revê pontos de vista. Esta perspectiva de atuação docente nos remete ao conceito de "professor reflexivo" proposto por Schön (1988), ou seja, as situações educacionais exigem do educador flexibilidade cognitiva e capacidade de desconstruir o problema aparente, para encontrar o problema existente, constituindo o que chama de practicum reflexivo. Nesse sentido, a competência de um bom profissional assenta-se no conhecimento tácito aliado ao conhecimento da ciência e das técnicas, trazendo-Ihes uma dimensão criativa. Esse conhecimento tácito, construído na prática profissional precisa ser mais valorizado na formação de novos profissionais.

Finalmente, a partir da análise dos dados do questionário, constatam-se as precárias condições de trabalho citadas pelos professores da rede pública de ensino, tais como: jornada de trabalho com número elevado de aulas; tempo escasso para planejamento; baixos salários; número excessivo de alunos por sala de aula; falta de material e espaço adequado; dificuldades em se envolver com cursos de especialização ou pós-graduação.

\section{Estudo II}

De acordo com as respostas dos professores às questões da primeira parte da entrevista, foi elaborado um quadro explicativo, conforme tabela 1: 
Tabela 1. Formação e perfil profissional.

\begin{tabular}{|c|c|c|c|c|c|c|}
\hline $\begin{array}{c}\text { Rrofessor } \\
\text { Questầ }\end{array}$ & 1 & 2 & 3 & 4 & 5 & 6 \\
\hline$(2)$ & 32 anos & 26 anos & 27 anos & 33 anos & 27 anos & 33 anos \\
\hline$(3)$ & 3 anos & 4 anos & 6 anos & 7 anos & 7 anos & 8 anos \\
\hline$(4)$ & 2 anos & 2 anos & 2 anos & $9 \mathrm{~ms}$ & 4 anos & 5 anos \\
\hline$(5)$ & $\begin{array}{c}\text { sim } \\
(1 \text { ano })\end{array}$ & não & não & $\begin{array}{c}\text { sim } \\
(5 \text { anos })\end{array}$ & não & sim \\
\hline$(6)$ & $\begin{array}{c}\text { Mestrado } \\
(\text { FSP-USP) }\end{array}$ & $\begin{array}{c}\text { Mestrando } \\
\text { (FE-USP) }\end{array}$ & não & não & $\begin{array}{c}\text { Mestrado } \\
\text { (EEFE-USP) }\end{array}$ & $\begin{array}{c}\text { Extensão (USP) } \\
\text { Mestrado (UNESP) } \\
\text { Doutorando (UNESP) }\end{array}$ \\
\hline
\end{tabular}

Obs.: (2)- Idade; (3)- Tempo de atuação profissional; (4)- Tempo como funcionário da rede pública; (5)Estágio ou aulas em outras instituições de ensino escolar, antes do ingresso na rede pública; (6)Realização de cursos de extensão universitária ou pós-graduação em Educação Física.

Um fator importante a ser destacado com relação à descrição dos dados, principalmente em referência às respostas fornecidas para a questão 6, é que a amostra pode ser considerada "privilegiada", no que diz respeito à formação acadêmica dos educadores, principalmente quanto à realização dos programas de pósgraduação em universidades públicas conceituadas. Esse fato pode ter influenciado as respostas que serão analisadas a seguir.

Com relação à primeira pergunta da segunda parte da entrevista, ficou evidente que cada professor valoriza um conhecimento específico como suporte principal para a intervenção profissional, como também consideram outra forma de conhecimento como adicional, direcionada à ação docente.

Um dos professores citou a bagagem cultural como primordial: "Bom, com relação à importância e o que eu tenho de conhecimento, eu acho que... Em primeira parte é a bagagem cultural que a gente recebe, que a gente constrói quando a gente está fazendo a faculdade, também a história de vida que a gente tem", corroborando os estudos de Tardif; Lessard e Lahaye (1991), onde os professores utilizam, em suas atividades cotidianas, conhecimentos práticos provenientes do mundo vivido, dos saberes do senso comum e das competências sociais. Suas técnicas não se apóiam nas ciências ditas positivas, mas, sobretudo nos saberes cotidianos, em conhecimentos comuns, sociais e baseados na linguagem natural.

Dois professores citaram o conhecimento técnico (desenvolvimento de conteúdos da Educação Física) como preponderantes. Primeiro professor: "Principalmente na nossa área, tem muita coisa ligada. Então, às vezes você vai trabalhar com músicas de roda, se você estiver trabalhando com as crianças pequenas. Você traz lá 'Os Escravos de Jó', alguma coisa assim, que a gente traz desde a nossa infância. Alguns jogos, são bem legais". Segundo professor: "Quem teve essa vivência, porque hoje em dia não tem mais essa vivência. Mas a gente que teve essa vivência, acho que isso ajuda bastante na hora de programar e planejar a aula". Estes depoimentos relacionam-se ao que é proposto por Macedo (2005) que estabelece a necessidade do conhecimento adequado dos conteúdos escolares e das características do desenvolvimento e aprendizagem de seus alunos.

Três professores apontaram o conhecimento didático no que diz respeito à prática pedagógica docente como principal conhecimento. Primeiro professor: “... Eu acredito que eu classificaria primeiramente o conhecimento didático, depois bagagem cultural e, por último, conhecimento técnico. Na formação, desde o início da formação, nesse sentido o da faculdade, até a formação continuada - no meu caso o mestrado, é onde você tem a 
oportunidade de refletir sobre o que você vai estar fazendo. Então vai te influenciar durante todo o, toda a sua atuação está muito ligada a sua formação...". Segundo professor: "Até é difícil separar, qual é o conhecimento mais importante, mas talvez se fosse hierarquizar os conhecimentos. Didáticos, principalmente relacionados ao próprio conteúdo da Educação Física. O que é o conteúdo, até definir o que seja o conteúdo da Educação Física, concomitante com isso os aspectos didáticos de como dar aula, talvez sejam prioritários...". Terceiro professor: "Mas aprender como estruturar uma aula, pontos a abordar, como dar continuidade, como dar seqüência de como trabalhar com os alunos, ajudou bastante, foi importante. Mas ainda falta aprender como utilizar formas variadas, de formas diferenciadas. Para não levar a aula sempre no mesmo ritmo, sempre de uma mesma forma, utilizando os mesmos materiais...". Autores como Ferreira (2001) e Imbernón (2000), defendem a perspectiva de que o educador deve deixar de ser visto como aquele que possui um determinado conhecimento formal estabelecido de antemão, para tornar-se capaz de analisar o contexto em mudança, repensando a teoria e redefinindo novas metodologias de atuação, condizentes com as necessidades de aprendizagem de uma sociedade em constante transformação. Ainda segundo Perrenoud, Paquay, Altet e Charlier (2001), o educador deixa de ser um técnico que aplica inovações prescritas por especialistas exteriores à escola, para converter-se no profissional que cria o processo de inovação a partir de uma reflexão ativa e crítica sobre o contexto educativo.

Em referência à segunda questão da segunda parte, quatro professores citaram a importância de um curso de formação continuada em Educação Física considerar a reflexão individual e coletiva entre os docentes, com relação à prática pedagógica desenvolvida no cotidiano da escola (intervenção profissional) aliada às diversas vertentes (correntes pedagógicas da Educação Física) adotadas na elaboração dos conteúdos e projetos pedagógicos aplicados. Primeiro professor: "Eu pensaria no recurso da pesquisa-ação; o próprio professor identificar problemas na sua prática e pensar em saídas para esses problemas...". Segundo professor: “...aí tem uma relação, por exemplo, dele professor - que trabalha na escola, com outros professores de outras escolas, ou professores que trabalham no ensino superior...". Terceiro professor: "Estudar as abordagens: abordagem desenvolvimentista, construtivista, crítico-superadora. Eu acho que todas as coisas trariam uma reflexão para os professores, no sentido de qual, porque eles estão usando cada conteúdo, objetivo...". Quarto professor: "...onde que eles querem chegar com as aulas que eles estão dando. Então direcionar o curso no sentido de trazer uma reflexão para o professor e, nesse sentido eu acho que a história da Educação Física seria muito importante".

Estes apontamentos inferem a necessidade de estratégias formativas que estimulem uma perspectiva crítico-reflexiva; que facilitem dinâmicas de auto-formação participada; permitindo aos educadores apropriar-se dos processos de formação. Através desta dinâmica, possibilitar que os educadores sejam protagonistas da implementação de inovações educativas e permitir que trabalhar e formar sejam atividades integradas onde os educadores encarem a sua formação como um processo permanente.

Ainda dentro desta perspectiva, Nóvoa (1995) defende um modelo de formação baseado na análise das práticas e na reflexão, cujo objetivo é formalizar os saberes oriundos da prática. Os procedimentos de formação estão voltados para a análise e reflexão das práticas vivenciadas pelo educador por meio de mediadores como a vídeoformação, verbalizações, entrevistas de esclarecimento e trabalho em grupo. A formação do professor reflexivo ocorre a partir de grupos de trabalho assessorados por um formador ou coordenador. Nesses grupos, permite-se a partilha de saberes, a troca de experiências e a consolidação de espaços de formação mútua em que formandos e formadores interagem de modo construtivo.

Outros dois professores apontaram como relevante para um curso de formação de professores, considerar a integração da disciplina de Educação Física com os demais componentes curriculares, incrementando, ao mesmo tempo, maior vivência de práticas pedagógicas em estágios de docência escolar. Primeiro professor: "Primeiro de tudo seria fazer com que a 
disciplina Educação Física fosse integrada as outras disciplinas. Que é um disparate muito grande, é uma visão ainda que aula de Educação Física é uma aula de brincadeira. Por mais que isso seja discutido, que seja tentado uma mudança... e o que poderia interligar com outras disciplinas, com outros assuntos”. Segundo professor: “...eu acho que seria mais importante dar uma carga, sei lá, de estágio. Ou alguma coisa, uma vivência prática para os professores. Antes dos professores entrarem numa sala de aula. Para eles poderem saber como lidar com determinadas situações que acontecem dentro da aula, e ele fica: Ai meu Deus, e agora. Agora o que é que eu faço. Ficarem puxando os cabelos, ficarem desesperados sem saber o que fazer...". Segundo Schön (2000), a prática profissional deve ser aprendida por meio da iniciação nas tradições da profissão. Mas, aprender com a prática não é apenas aprender receitas instrumentais para solucionar problemas, e sim, compreender a forma como profissionais competentes raciocinam sobre situações indeterminadas da prática.

Com relação à terceira pergunta dirigida aos professores, quanto à análise das transformações culturais ocorridas ao longo da história que por ventura pudessem interferir na ação do profissional docente na escola, as respostas apresentadas consideram que, por muito tempo, a profissão docente foi caracterizada apenas em sua dimensão técnica, ou seja, o professor era visto como um mero aplicador de decisões extrínsecas a ele, que deveriam ser colocadas em prática: "Eu acho que culturalmente, apesar da gente ter tido no início dos anos 80 uma pluralização das abordagens, eu acho que por questões culturais e de grande influência da mídia a gente tem retornado muito a esportivização da área. Apesar de academicamente a gente não estar discutindo isso, isso é uma realidade muito forte na escola, sobretudo a escola pública; pelo menos a escola que eu atuei isso estava muito presente...".

O estudo da prática pedagógica e da escola ganha qualidade com a análise conjunta do contexto cultural mais amplo. Portanto, ao ser analisada, a escola deve ser inserida no ideal educacional da cultura e da sociedade (BRUNER, 2001). No caso específico da Educação Física escolar, a influência do esporte de rendimento decorrente da exploração pela mídia dos Jogos Olímpicos ou dos campeonatos nacionais e internacionais de futebol, tem influenciado fortemente a visão dos pais, da sociedade e do poder público em geral, referente ao papel da Educação Física na escola.

Ainda com relação às respostas apresentadas: "Em relação aos aspectos sociais, eu acho que dependendo principalmente de onde o professor trabalha, ele tem que saber muito lidar com o aluno. Nem sempre os professores vão conseguir aula em escolas de um bom nível social. Apesar de estaduais, você tem alunos com uma condição sócio-econômica muito boa. Então você vai lidar com questões sociais do tipo, tráfico de drogas nas escolas, o professor vai ter que saber trabalhar com isso. Então eu acho importante o professor também, quando ele está lá fazendo a preparação dele, para poder entrar no mercado. Acho que tem que fazer parte da formação dele. Porque ele vai fazer o quê? Vai matar o aluno que está traficando na frente dele. Ele tem que saber lidar com esse tipo de situação...". Perrenoud, Paquay, Altet e Charlier (2001) afirmam que, a ênfase ou intensidade de mobilizar um ou outro recurso vai depender da relação que o profissional mantiver com seus alunos, pois ela estará vinculada muito mais à subjetividade ao invés do que muitos pesquisadores supunham ou gostariam de admitir. Nesse processo de construção do conhecimento, entra em cena a inserção do professor nas relações sociais, seu itinerário pessoal ou familiar, sua identidade e a imagem de si mesmo.

Além disso, a complexidade e dinâmica inerentes às relações sociais e ao mundo do trabalho na sociedade atual requerem, dos profissionais que nele atuam, competências diferenciadas àquelas exigidas em tempos antigos, uma vez que a necessidade de conhecimentos cada vez mais diversificados é constante. Pode-se observar esse aspecto no depoimento dos professores sobre temas como gravidez precoce, drogas, sexualidade, entre outros: "Questão de você ser quase que mãe e pai de aluno, você tem que dar instruções de como o aluno tem que se vestir. Coisa de higiene, porque dependendo do lugar que 
você está, os alunos não têm isso, eles não têm essas noções. Algumas noções de doenças sexualmente transmissíveis. Esse negócio de pegar crianças com 15 anos, grávida. Como é o caso na escola que eu trabalho".

No que diz respeito às transformações políticas, verifica-se que os professores entrevistados estão bem conscientes da ineficácia das ações governamentais atuais. Identifica-se a falta de continuidade por parte das administrações que assumem o poder, interrompendo projetos em andamento em vez de aperfeiçoá-los. Como exemplo deste tipo de gestão é citada a "progressão continuada" no estado de São Paulo, que visa manter o aluno na escola por um período de tempo mais amplo e que tem sua continuidade ameaçada a cada eleição. Outro exemplo, comentado por um dos professores entrevistados, como ação política inócua, é a aplicação do "provão" sem o enfrentamento dos problemas já conhecidos, tais como: falta de estrutura nas escolas - biblioteca; materiais; espaços adequados e salas superlotadas. Além disso, os professores entrevistados também criticaram as propostas de bônus por desempenho acadêmico dos alunos, ignorando a formação inicial inadequada dos professores, as dificuldades em se aperfeiçoar profissionalmente, bem como, as condições de trabalho.

Aspectos da legislação são apontados como evidências de uma Educação Física voltada somente para a prática de atividades físicas, não implicando em um saber escolar, na medida em que os alunos do ensino médio noturno são legalmente dispensados das aulas por motivo de trabalho ou de gravidez, por exemplo. Finalmente, foi observada a desvalorização docente nas últimas décadas o que tem prejudicado a profissão e a instituição escolar.

Em referência às transformações econômicas, os principais problemas enfrentados pelos professores e pela escola atualmente tornam-se evidentes, tais como: pouco investimento em cursos de formação continuada; escassa reposição de materiais e equipamentos; burocracia do governo na liberação de verbas para a educação básica; dificuldade financeira dos professores, obrigando-os a adotarem jornadas de trabalho com número elevado de aulas e, agravando esta situação, constatam-se precárias condições de trabalho.

Segundo os professores, o poder público tem considerado como primordial 0 aumento substancial do número de alunos ingressantes no sistema educacional, assim como a manutenção dos que nele se encontram. Entretanto, tem-se descuidado da qualidade do ensino oferecido, não investindo na melhoria estrutural das escolas, não oferecendo planos de carreira mais atrativos e, com isso, evitando-se a evasão de docentes comprometidos com o sistema público de ensino.

As constatações de Imbernón (2000) sobre as características da sociedade moderna são pertinentes, uma vez que algumas das políticas públicas evidenciadas na fala dos professores expressam práticas e idéias neoliberais mediante padronização de índices de desempenho e avanço do gerencialismo educativo com bônus salarial a partir desses desempenhos.

Com relação aos aspectos educacionais, apesar de haver diferenças significativas entre os aportes teóricos que procuram estudar e promover a compreensão da noção de competência, todos eles, críticos ou assertivos, parecem não se diferenciar naquilo que é básico a esta noção: o entendimento da competência como uma capacidade de ação para a qual são mobilizados alguns recursos, tais como conhecimentos, qualidades, habilidades e aptidões que possibilitam o estudo, a investigação, a reflexão e, fundamentalmente, a decisão sobre o que se refere à intervenção educacional (SORIANO, 1998).

Concluindo, as respostas dos professores nos remetem às dificuldades encontradas e, portanto, às competências necessárias à atuação docente na escola atual. Esta é uma escola que lida com uma população ampla e diversificada e não mais com uma pequena parcela da população que se constituía de outras estruturações familiares onde os pais participavam com mais freqüência da vida escolar de seus filhos. Outro aspecto apontado relaciona-se ao que é valorizado atualmente pelos alunos e familiares no que diz respeito à função da escola. Tudo indica um pragmatismo voltado à preparação para o mundo do trabalho, dificultando a apreensão de valores relacionados à importância do conhecimento como bem cultural e crescimento do ser humano.

\section{Considerações finais}


De acordo com o objetivo da pesquisa analisar as competências necessárias aos professores de Educação Física da educação básica, na perspectiva dos docentes da rede pública de ensino do estado de São Paulo inferiu-se que os docentes julgam importante mobilizar determinados conhecimentos durante a prática docente, tais como: conhecimentos didático-pedagógicos, conhecimentos técnicos e bagagem cultural. A partir das respostas dos professores, contatou-se que esses conhecimentos estão hierarquizados para alguns e associados para outros sem uma valoração dos mais importantes. Todavia, destaca-se que esses conhecimentos devem estar inseridos no contexto atual e devem considerar as transformações culturais, sociais, políticas, econômicas e educacionais ocorridas ao longo da história.

Foi enfatizada a relevância da formação continuada para os professores de Educação Física, que a consideram imprescindível na complementação à formação inicial.

Ficou evidenciado que as condições econômicas e trabalhistas dos professores, como por exemplo, a baixa remuneração, pouco investimento em formação continuada, planos de carreira pouco atrativos, escassez de materiais e equipamentos, extensas jornadas de trabalho, número excessivo de alunos por sala de aula, políticas públicas não condizentes com as necessidades reais do sistema educacional brasileiro, são fatores que contribuem para a dificuldade de permanência do docente na escola pública.

É importante destacar que a amostra utilizada nas entrevistas constituiu-se de profissionais com formação diferenciada - cursos de extensão e pós-graduação - o que pode ter influenciado nos resultados, uma vez que, os cursos de pósgraduação latu e strictu senso possibilitam aprofundamento teórico e reflexão sobre a prática docente durante a própria atuação profissional.

Há que se reconhecer que os professores vem assumindo variadas funções e atribuições fora do ambiente escolar, impulsionados pela necessidade de melhores ganhos financeiros, melhores condições de trabalho e reconhecimento profissional. A consequência de todo este processo é o progressivo "esvaziamento docente" do sistema público de ensino, provocado pela evasão destes profissionais para outros setores da economia.

Finalizando, esses resultados podem fornecer subsídios para cursos de formação de professores questionando aspectos curriculares dos paradigmas acadêmicos existentes. Um dos principais aspectos é o de que a docência e a vida escolar no que se referem aos seus valores, metas e práticas cotidianas, devem ser objeto privilegiado de todo projeto que vise a preparação para o exercício profissional na escola contemporânea.

\section{Referências}

BRASIL (Ministério da Educação e do Desporto, Secretaria de Educação Fundamental). Referenciais para Formação de Professores Polivalentes. Versão preliminar. Brasília: MEC/SEF, 1998.

BRUNER, J. A cultura da educação. Tradução de Marcos A. G. Domingues. Porto Alegre: Artmed, 2001.

\section{FERRAZ, O. L. Educação Física na educação infantil e o referencial curricular nacional: significado para os professores. Tese (Doutorado em Educação), Faculdade de Éducação da Universidade de São Paulo - USP, 2000.}

FERREIRA, F. I. A formação e os seus efeitos: do modelo escolar à formação em contexto. In: OLIVEIRA-FORMOSINHO, Julia; FORMOSINHO, João. Associação Criança: Um Contexto de Formação em Contexto. Braga: Livraria Minho, 2001.

\section{IMBERNÓN, F. Formação Docente e}

Profissional: formar-se para a mudança e incerteza. Coleção Questões da nossa Época, n.77. São Paulo: Cortez, 2000.

LE BOTERF, G. Desenvolvendo a competência dos profissionais. Tradução de Patrícia C. R. Reuillard. Porto Alegre: Artmed, 2003.

\section{LÜDKE, M.; ANDRÉ, M. E. D. A. Pesquisa em} educação: abordagens qualitativas._São Paulo: E.P.U., 1986.

MACEDO, L. A reflexão na prática docente. Instituto de Psicologia da Universidade de São Paulo. Mimeo. São Paulo, 2005.

MORFORD, W. P. Toward a profession not a craft. Quest, v.18, p. 88-93, 1972.

NONAKA, I. ; TAKEUCHI, H. Criação do conhecimento na empresa. Rio de Janeiro: Campus, 1997. 
NÓVOA, A. Formação de professores e profissão docente. In: NÓVOA, António (Coord.). Os professores e a sua formação. $2^{\mathrm{a}} \mathrm{ed}$. Lisboa: Dom Quixote, 1995. p.15-34.

PERRENOUD, P.; PAQUAY, L.; ALTET, M.; CHARLIER, É. Formando professores profissionais: quais estratégias? Quais competências? Porto Alegre: Artmed, 2001.

RIOS, T. A. Compreender e ensinar. $5^{\mathrm{a} e d . ~ S a ̃ o ~}$ Paulo: Cortez, 2005.

SCHÖN, D. Formar professores como profissionais reflexivos. In: NÓVOA, António (Coord.). Os professores e sua formação. Lisboa: Dom Quixote, 1988.

SCHÖN, D. Educando o profissional reflexivo: um novo design para o ensino e aprendizagem. Tradução de Roberto Cataldo Costa. Porto Alegre: Artmed, 2000.

SORIANO, J. B. Educação física: competência profissional e atuação no mercado de trabalho. In: Semana da Educação Física. Anais. São Paulo: USJT, 1998. p.44-59.

TARDIF, M.; LESSARD, C.; LAHAYE, L. Les enseignants des ordrers d' enseignement primaire et secondaire face aux savoirs - Equisse d'une problématique du savoir enseignant. Sociologie et Sociétés. Vol.23, n.1, 1991. p.5570.

THOMAS, J. R.; NELSON, J. K. Métodos de Pesquisa em Atividade Física. $3^{\mathrm{a} e d .}$. Porto Alegre: Artmed, 2002.

TRIVIÑOS, A. N. S. Introdução à pesquisa em ciências sociais: a pesquisa qualitativa em educação. São Paulo: Atlas, 1987.

UNIVERSIDADE DE SÃO PAULO (Pró-Reitoria de Graduação, Comissão Permanente dos Cursos de Licenciatura). Projeto de formação de professores na USP: São Paulo, 2004.
Recebido em: 17 de agosto de 2009. Aceito em: 05 de fevereiro de 2010.

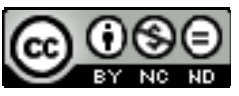

Motriz. Revista de Educação Física. UNESP, Rio Claro, SP, Brasil - elSSN: 1980-6574 - está licenciada sob Licença Creative Commons

\section{Endereço:}

Rodrigo Nuno Peiró Correia

Rua Tucuna, 770, apto. 84, Pompéia.

São Paulo SP Brasil

05021-010

Telefone: (11) 9114-0530

e-mail: rnpc@usp.br 